\title{
Premalignant Hematologic Condition
}

National Cancer Institute

\section{Source}

National Cancer Institute. Premalignant Hematologic Condition. NCI Thesaurus. Code C27274.

A hematologic disorder which does not display the morphologic and/or clinical characteristics of an overt malignancy. Representative examples include atypical lymphoproliferative disorders and myelodysplastic syndromes. 